\title{
HUBUNGAN SISA KLOR DENGAN KELUHAN IRITASI KULIT DAN MATA PADA PEMAKAI KOLAM RENANG HOTEL DI WILAYAH KOTA YOGYAKARTA
}

\author{
Teddy Permana, Dyah Suryani \\ Fakultas Kesehatan Masyarakat, Universitas Ahmad Dahlan, Yogyakarta
}

\begin{abstract}
Background: Public places such as public baths and swimming pools are used as a gathering place by many people have potency to be a medium of disease transmission. Direct contact among visitors can transmit disease germs from one to the other visitors. Moreover, the contact can be a deployment medium of a disease. This study aimed to determine the relationship between chlorine residue with the complaints of skin and eye irritations of swimmingpool users in Yogyakarta hotels.

Methods: The research was an observational analytic study by using cross sectional design. Sampling of the research uses systematic random sampling and consists of 48 respondents. Research tools used are questionnaires and laboratory tests. Data analysis uses univariate and bivariate analysis with a statistical test ChiSquare (X2).

Results: Results of the study showed that 28 respondents (58.3\%) have complaints and 20 respondents $(41.7 \%)$ do not have complaints. From six water samples taken from swimming pool, 4 samples (66.7\%) do not qualify and 2 samples (33.3\%) are eligible. Bivariate analysis found that there was a significant relationship between chlorine residue with the complaints of skin and eye irritations of swimming pool users in Yogyakarta hotels $(p=0.038)$ smaller than alpha $(\alpha=0.05), \mathrm{RP}=1,83$.

Conclusion: There was a relationship between residual chlorine with the complaints of skin and eye irritations of swimming pool users in Yogyakarta hotels.
\end{abstract}

Keywords: Chlorine Residue, Skin and eye irritation complaints, Swimming Pool

\section{PENDAHULUAN}

Salah satu langkah pengelolaan kolam renang yang dilakukan adalah pemantauan dan interpretasi data kualitas air, mencakup kualitas fisika, kimia, dan biologi. Namun, sebelum melangkah pada tahap pengelolaan, diperlukan pemahaman yang baik tentang terminology, karakteristik, dan interkoneksi parameter - parameter kualitas air. ${ }^{1}$

Tempat-tempat umum yang sering dijadikan tujuan berkumpulnya manusia misalnya pemandian umum dan kolam renang, merupakan media yang cukup baik dalam penularan penyakit. Secara langsung kontak yang terjadi diantara pengunjung dapat menyebabkan transmisi kuman penyakit dan dengan mobilitas yang tinggi sekaligus dapat merupakan media penyebarluasan penyakit. ${ }^{2}$

Proses pemberian klorin ke dalam air yang telah menjalani proses filtrasi dan merupakan langkah yang maju dalam proses purifikasi air. Klorin ini banyak digunakan dalam pengolahan limbah industri, air kolam renang, dan air minum di negara-negara sedang berkembang karena sebagai disinfektan, biayanya relative lebih murah, mudah dan efektif. ${ }^{3}$

Klorin sudah umum diketahui oleh masyarakat kita dengan sebutan klor atau kapur klor karena banyak digunakan sebagai bahan pemutih bleaching agent yang mengandung sodium hipoklorit atau kalsium hipoklorit dan dikenal dengan nama kaporit. Kaporit dipergunakan juga untuk campuran dalam detergen. Senyawa 
kaporit ini menghasilkan gas klorin yang cukup beracun, sehingga dapat dipergunakan sebagai desinfektan dan dapat menyebabkan iritasi pada kulit dan lapisan mukosa. ${ }^{4}$

Persyaratan menurut Permenkes RI No : 416/Menkes/Per/IX/1990 dan Permenkes RI No: 061/Menkes/Per/l/1991, bahwa kolam renang harus memenuhi kualitas air yang telah ditetapkan secara fisik, kimia, bakteriologis. Air kolam renang secara bakteriologis (koliform total) yang diperbolehkan adalah nihil (0) per $100 \mathrm{ml}$ air, sedangkan secara kimia (sisa klor) yang dianjurkan $0,2-0,5 \mathrm{mg} / \mathrm{l}$, sehingga untuk memenuhi syarat bakteriologis ini umumnya dilakukan desinfeksi pada air kolam renang.

Maka dari uraian di atas peneliti ingin melakukan penelitian dengan judul " Hubungan Sisa Klor dengan Keluhan Iritasi Kulit dan Mata Pada Pemakai Kolam Renang Hotel di Wilayah Kota Yogyakarta “

\section{METODE}

Jenis penelitian ini adalah analitik observasional dengan rancangan cross sectional. Subjek yang digunakan adalah pemakai kolam renang hotel. Analisis data hasil penelitian ini dilakukan dengan analisis univariat dan bivariat. Analisis Analisis univariat digunakan untuk menganalisa karakteristik dan variabel dengan cara mendeskripsikan dan menghitung distribusi dan proporsinya. Sedangkan analisis bivariat digunakan untuk mengetahui hubungan antara dua variabel penelitian. Data kemudian dianalisis dengan uji Chi-square untuk mengetahui hubungan antara dua variabel sehingga dapat disimpulkan adanya hubungan antara variabel bebas dan variabel terikat.

\section{HASIL PENELITIAN DAN PEMBAHASAN}

\section{A. Hasil Penelitian}

a. Analisis Univariat

\section{1). Sisa Klor}

Sisa klor pada sampel air kolam renang hotel bintang 3 dan 4 di wilayah kota Yogyakarta diperoleh melalui uji laboratorium. Uji ini menggunakan alat komperator lovibond, tabung cuvet bervolume $10 \mathrm{ml}$, reagen DPD 1 dan 3 . Pengujian dilakukan maksimal 3 jam dari pengambilan sampel air kolam renang. Distribusi frekuensi sisa klor pada sampel air kolam renang hotel bintang 3 dan 4 di wilayah kota Yogyakarta dapat dilihat pada tabel berikut:

Tabel 1. Analisis Univariat Sisa Klor Pada Sampel Air Kolam Renang Hotel Bintang 3 dan 4 di Wilayah Kota Yogyakarta Tahun 2012

\begin{tabular}{cccc}
\hline \multirow{2}{*}{ No. } & Kategori & \multicolumn{2}{c}{ Frekuensi } \\
\cline { 3 - 4 } & Memenuhi Syarat & Jumlah & Persentase (\%) \\
\hline 1. & (sampel air) & 3 & 33,3 \\
\hline 2. & $\begin{array}{c}\text { Tidak Memenuhi } \\
\text { Syarat }\end{array}$ & 4 & 66,7 \\
\hline & Total & 6 & 100 \\
\hline
\end{tabular}

Tabel 1 menunjukkan bahwa sisa klor pada sampel air kolam renang hotel bintang 3 dan 4 di wilayah kota Yogyakarta didominasi oleh sampel 
air dengan kategori tidak memenuhi syarat yaitu sebanyak 4 sampel air $(66,7 \%)$, sedangkan sampel air dengan kategori memenuhi syarat yaitu sebanyak 2 sampel air (33,3\%), dengan demikian dapat disimpulkan bahwa sisa klor pada sampel air kolam renang hotel bintang 3 dan 4 di wilayah kota Yogyakarta tidak memenuhi syarat.

2). Keluhan Iritasi Kulit dan Mata

Keluhan iritasi kulit dan mata pada pemakai kolam renang hotel bintang 3 dan 4 di wilayah kota Yogyakarta, pada penelitian ini diukur dengan menggunakan kuesioner yang terdiri dari 5 pertanyaan tentang keluhan terjadinya iritasi kulit dan mata. Dari 5 pertanyaan tersebut jika ada responden yang menjawab "Ya" maka dapat dikatakan bahwa responden tersebut mengalami keluhan iritasi kulit dan mata. Distribusi frekuensi keluhan iritasi kulit dan mata pada pemakai kolam renang hotel bintang 3 dan 4 di wilayah kota Yogyakarta dapat dilihat pada tabel berikut:

Tabel 2. Analisis Univariat Keluhan Iritasi Kulit dan Mata Pada Pemakai Kolam Renang Hotel Bintang 3 dan 4 di Wilayah Kota Yogyakarta Tahun 2012

\begin{tabular}{cccc}
\hline \multirow{2}{*}{ No. } & \multirow{2}{*}{ Kategori } & \multicolumn{2}{c}{ Frekuensi } \\
\cline { 3 - 4 } & Ada Keluhan & 28 & Jumlah (orang) \\
\hline 1. & $\begin{array}{c}\text { Tidak Ada } \\
\text { Keluhan }\end{array}$ & 20 & 41,7 \\
\hline 2. & Total & 48 & 100 \\
\hline
\end{tabular}

Tabel 2 menunjukkan bahwa keluhan iritasi kulit dan mata pada pemakai kolam renang hotel bintang 3 dan 4 di wilayah kota Yogyakarta didominasi oleh responden yang menjawab "Ya" yaitu sebanyak 28 responden $(58,3 \%)$, dan responden yang menjawab "Tidak" sebanyak 20 responden $(41,7 \%)$. Dari hasil diperoleh, responden yang mengalami keluhan iritasi kulit dan mata lebih mendominasi jumlahnya dibandingkan dengan responden yang tidak mengalami keluhan iritasi kulit dan mata, dengan demikian dapat disimpulkan bahwa adanya keluhan iritasi kulit dan mata pada pemakai kolam renang hotel bintang 3 dan 4 di wilayah kota Yogyakarta.

b. Analisis Bivariat

Hasil Analisis bivariat hubungan antara sisa klor dengan keluhan iritasi kulit dan mata pada pemakai kolam renang hotel bintang 3 dan 4 di wilayah kota Yogyakarta, dapat dilihat pada Tabel 3 berikut : 
Tabel 3. Hasil Uji Chi-Square Hubungan Antara Sisa Klor Dengan Keluhan Iritasi Kulit dan Mata Pada Pemakai Kolam Renang Hotel Bintang 3 dan 4 di Wilayah Kota Yogyakarta Tahun 2012

\begin{tabular}{|c|c|c|c|c|c|c|c|c|c|}
\hline \multirow{3}{*}{ Sisa Klor } & \multicolumn{4}{|c|}{$\begin{array}{c}\text { Keluhan Iritasi Kulit } \\
\text { dan Mata }\end{array}$} & \multirow{2}{*}{\multicolumn{2}{|c|}{ Total }} & \multirow{3}{*}{$\mathrm{RP}$} & \multirow{3}{*}{ Cl 95\% } & \multirow{3}{*}{ Sig } \\
\hline & \multicolumn{2}{|c|}{$\begin{array}{c}\text { Ada } \\
\text { Keluhan }\end{array}$} & \multicolumn{2}{|c|}{$\begin{array}{c}\text { Tidak Ada } \\
\text { Keluhan }\end{array}$} & & & & & \\
\hline & $\mathrm{n}$ & $\%$ & $\mathrm{n}$ & $\%$ & $\mathrm{~N}$ & $\%$ & & & \\
\hline $\begin{array}{c}\text { Tidak } \\
\text { Memenuhi } \\
\text { Syarat }\end{array}$ & 22 & 45,8 & 10 & 20,8 & 32 & 66,7 & & & \\
\hline $\begin{array}{c}\text { Memenuhi } \\
\text { Syarat }\end{array}$ & 6 & 12,5 & 10 & 20,8 & 16 & 33,3 & 1,83 & $\begin{array}{l}0, / 7- \\
0,960\end{array}$ & 0,038 \\
\hline Total & 28 & 58,3 & 20 & 41,7 & 48 & 100 & & & \\
\hline
\end{tabular}

Berdasarkan analisis bivariat yang dilakukan ternyata syarat Chi-Square terpenuhi karena tidak terdapat nilai expected-nya kurang dari 5, Sehingga untuk melihat hubungan antara variabel bebas ( sisa klor) dengan variabel terikat ( keluhan iritasi kulit dan mata ) dapat dilakukan dengan melihat nilai signifikansi pada pearson chi-square yaitu 0,038 maka Ho ditolak, dengan demikian ada hubungan antara sisa klor dengan keluhan iritasi kulit dan mata pada pemakai kolam renang hotel bintang 3 dan 4 di wilayah kota Yogyakarta. Nilai Confidence Interval (Cl) sebesar 0,77 - 0,960. Hal ini juga menunjukkan bahwa ada hubungan yang bermakna antara sisa klor dengan keluhan iritasi kulit dan mata pada pemakai kolam renang hotel bintang 3 dan 4 di wilayah kota Yogyakarta. Sedangkan dilihat dari nilai Ratio Prevalen (RP) adalah 1,83 yang artinya air kolam renang dengan sisa klor yang tidak memenuhi syarat dapat menyebabkan terjadinya keluhan iritasi kulit dan mata pada pemakai kolam renang 1,83 kali lebih besar dibandingkan dengan air kolam renang yang memiliki sisa klor memenuhi syarat.

\section{B. Pembahasan}

a. Sisa Klor Pada Sampel Air Kolam Renang Hotel Bintang 3 dan 4 di Wilayah Kota Yogyakarta.

Berdasarkan data primer yang diperoleh $66,7 \%$ sampel air kolam renang hotel bintang 3 dan 4 di Wilayah Kota Yogyakarta tidak memenuhi syarat dengan sisa klor $<0,2$ atau $>0,5 \mathrm{mg} / \mathrm{l}$ berdasarkan uji laboratorium dengan menggunakan komparator lovibond. Pada umumnya sampel air kolam renang hotel yang tidak memenuhi syarat menggunakan klorin berbentuk serbuk, karena klorin berbentuk serbuk ini banyak di pasaran selain itu harganya lebih murah dan mudah dalam penggunaannya. Selain itu, cara pemberian klorin pada air kolam renang oleh petugas tidak sesuai dengan ketentuan yang ditetapkan dalam pemberian klorin. Sedangkan sampel air kolam renang hotel bintang 3 dan 4 di Wilayah Kota Yogyakarta yang memenuhi syarat adalah $33,3 \%$. Sampel air kolam renang dikatakan memenuhi syarat jika kadar sisa klor 0,2-0,5 mg/l. ${ }^{5}$ 
b. Keluhan Iritasi Kulit dan Mata Pada Pemakai Kolam Renang Hotel Bintang 3 dan 4 di wilayah Kota Yogyakarta.

Berdasarkan hasil penelitian dapat diketahui bahwa didominasi oleh responden yang mengalami keluhan iritasi kulit dan mata sebanyak 58,3 \%. Cara penilaian dilakukan dengan melihat adanya jawaban "Ya" pada lima pertanyaan yang diajukan. Hal ini terkait dengan lebih dominannya sampel air kolam renang dengan kadar sisa klor yang tidak memenuhi syarat.

c. Hubungan Sisa Klor dengan Keluhan Iritasi Kulit dan Mata Pada Pemakai Kolam Renang Hotel Bintang 3 dan 4 di Wilayah Kota Yogyakarta.

Berdasarkan hasil uji statistik menunjukkan ada hubungan sisa klor dengan keluhan iritasi kulit dan mata. Nilai signifikansi 0,038 $(p<0,05)$, maka Ho ditolak sehingga menunjukkan ada hubungan antara sisa klor dengan keluhan iritasi kulit dan mata. Serta mengetahui besarnya pengaruh dapat dilihat dari nilai Ratio Prevalen (RP), yaitu 1,83. Ini artinya air kolam renang dengan sisa klor yang tidak memenuhi syarat dapat menyebabkan terjadinya keluhan iritasi kulit dan mata pada pemakai kolam renang 1,83 kali lebih besar dibandingkan dengan air kolam renang yang memiliki sisa klor memenuhi syarat.

\section{SIMPULAN DAN SARAN}

\section{A. Simpulan}

1. Sisa klor pada sampel air kolam renang hotel bintang 3 dan 4 di Wilayah Kota Yogyakarta tergolong tidak memenuhi syarat dengan kategori jumlah $66,7 \%$.

2. Keluhan iritasi kulit dan mata pada pemakai kolam renang hotel bintang 3 dan 4 di Wilayah Kota Yogyakarta sebanyak 28 orang (58,3\%), sedangkan 20 orang $(41,7 \%)$ yang tidak mengalami keluhan.

3. Ada hubungan antara sisa klor dengan keluhan iritasi kulit dan mata pada pemakai kolam renang hotel di Wilayah Kota Yogyakarta.

\section{B. Saran}

1. Dinas Kesehatan Kota Yogyakarta

Menjadi bahan masukan bagi Dinas Kesehatan Kota Yogyakarta dalam pengambilan keputusan berkaitan dengan upaya peningkatan kualitas air kolam renang. Seperti memberikan teguran apabila ditemukan sisa klor yang tinggi pada air kolam renang hotel di wilayah Kota Yogyakarta.

2. Pengelola kolam renang

Diharapkan dapat menjadi bahan pertimbangan dalam rangka perencanaan dan upaya pengendalian terhadap risiko pencemaran kolam renang. Antara lain melakukan pemeriksaan yang teratur dengan mengacu pada peraturan yang ada.

3. Bagi peneliti lain

Diharapkan meneliti air kolam renang secara mikrobiologi yaitu pemeriksaan E.coli. yang bertujuan untuk mengetahui berapa banyak bakteri E.coli yang terkandung dalam air kolam berenang dan disesuaikan dengan peraturan yang ada. 


\section{DAFTAR PUSTAKA}

1. Effendi, H., Telaah Kualitas Air Bagi Pengelolaan Sumber Daya Air dan Lingkungan Perairan, Kanisius, Yogyakarta, Hal, 11, 12, 2003.

2. Leonardus, "Jumlah Bakteri Yang Terdapat Pada Pemandian Umum Water Boom Dengan Menggunakan Metode Angka Lempeng Total D Kabupaten Pangkep", Jurnal Media Analisis Kesehatan, Vol 1, No 1, Politeknik Kesehatan Makasar, Hal, 2, 2010.

3. Chandra , B., Pengantar Kesehatan Lingkungan, Penerbit Buku Kedokteran EGC, Jakarta, Hal, 55, 57, 2005.

4. Yuningsih," Pengaruh Cemaran Beberapa Senyawa Toksik Dalam Air Minum Terhadap Ternak", Jurnal Wartazoa, Vol 15, No 2, Balai Penelitian Veteriner, Bogor, Hal, 99, 2005.

5. Departemen Kesehatan RI., Peraturan Menteri Kesehatan Nomor 416/MENKES/PER/IX/1990, Tentang persyaratan kolam renang dan pemandian umum, Ditjen PPM dan PLP, Jakarta, 1990. 